\title{
Woman's Awareness about Initiation and Continuation of Breast feeding among Cesarean Section at Baghdad City- Iraq.
}

\author{
Iqbal Majeed Abbas Prof. PhD. \\ Maternal and Child Health Nursing Department, College of Nursing, University of Baghdad, Iraq
}

\begin{abstract}
Background: Breast feeding is the best way to provide unique biological and emotional effects on mothers and their newborn babies.

Objectives: To identify women's awareness about initiation and continuation of breastfeeding among cesarean section and predict the variables which contribute in initiation and continuation of breastfeeding.

Methodology: Non probability - a purposive sample of 30 women who had caesarean section and follow them for the first month after birth at Fatima Al-Zahra'a Maternity and Pediatric Teaching Hospital through the period from 16 May to 2 August 2011. Questionnaire developed by the researcher was based on review of literature and related studies and background experience as a tool of data collection. It was consisted of four parts (demographic, reproductive, initiation and continuation of breastfeeding). Content validity was carried out through eleven experts. A pilot study was conducted to test the reliability of the questionnaire and descriptive and inferential statistics were used to analysis of data.

Results: Results of the study revealed that $43.3 \%$ of study sample initiation of breastfeeding during 24 hours after cesarean section, $76.7 \%$ of them had continued breastfeeding, $26 \%$ of them had exclusive breastfeeding. Prediction of six variables which contribute in initiation and continuation of breast feeding (age, parity, number of alive children, age at marriage, place of previous delivery and previous initiation of breastfeeding).

Conclusions: Most of the study sample did not aware about the exclusive breastfeeding; one quarter of them had discontinuation of breastfeeding due to inadequate of their milk and newborn refused to take the breast during breastfeeding.

Recommendations: Reactivated the role of Baby Friendly hospital Initiative in promoting breastfeeding by implementation of ten steps successful breastfeeding and counseling women during pregnancy and immediate postpartum about initiation and maintenance of breastfeeding for six months after birth.
\end{abstract}

Key words: - Awareness, Breastfeeding, Cesarean Section, Continuation and Initiation.

\section{INTRODUCTION}

WHO estimates that worldwide only 35\% of children between birth and their fifth month are breastfed exclusively. In order to achieve the Millennium Development Goal (MDG) of reduction of child mortality, infant breastfeeding has been identified as one of the major intervention areas both globally and nationally. Extensive research in various countries has provided evidence that breastfeeding has clear health benefits for infants as well as the mother ${ }^{(1)}$. The current breastfeeding goals for Healthy People 2010 are that $75 \%$ of women breastfeed in the early postpartum period (initiation), 50\% of women remain breastfeeding at 6 months and $25 \%$ of women remain breastfeeding at one year ${ }^{(2)}$. In Iraq Multiple Indicator Cluster Survey 2006 appear only 31 percentage of women started breastfeeding within one hour of birth, with this percentage increasing to 85 percent when considering breastfeeding within one day of birth. Women differed in the timing of initial breastfeeding according to governorates, particularly when considering initiation of breastfeeding within one hour. Initial breastfeeding also varied with area of residence, increasing slightly from metropolitan to other urban to rural areas. A study in Mexico shows that $\mathrm{C} / \mathrm{S}$ is a risk factor for not initiating breastfeeding and for breastfeeding for less than one month, but it is unrelated to the duration of breastfeeding among women who breastfeed their babies for one month or more ${ }^{(3)}$. Researcher tries to investigate the importance of initiation and maintenance of breastfeeding as a simple and cheap method that fight the infectious diseases which increase the economic and medical burdens, especially in a developing society like Iraq. Objectives of this study are to identify women's awareness about initiation and continuation of breastfeeding among cesarean section and predict the variables which contribute in initiation and continuation of breastfeeding.

\section{METHODOLOGY}

A descriptive analytic design was conducted at Fatima Al-Zahra'a Maternity and pediatric Teaching Hospital from $16^{\text {th }}$ May to $2^{\text {nd }}$ August 2011. Non probability - a purposive sample was utilized to select the research sample. Questionnaire developed by the researcher was based on review of literature and related studies and background experience, as a tool of data collection. It was consisted of four parts (demographic, 
reproductive, initiation and continuation of breastfeeding), initiation of breastfeeding questionnaire items were rates and scored to two items as two for yes \& one for no, while the numeric values for the negatives items of the scale were one for yes $\& 1$ for yes, so the cut - off - point was 1.5 . Content validity was carried out through eleven experts. Pilot study was carried out on (13) women postoperative cesarean section to determine the reliability of questionnaire through use split-half approach and computing of reliability coefficient were $(0.906)$ for knowledge questions \& (0.853) for practical questions. Data was collected from 42 postoperative women who have cesarean section $28.5 \%$ of them were dropped out and the remaining of them was 30 . Before each interview the researcher explained to the participant the significance of the research study and they were voluntary and can be withdrawn from the study at any stage. The data was collected from study sample after full recovery through the utilization of the study instrument, and interview technique for each postoperative woman, and reviewing their medical records as means of data collection and follow up during postpartum discharge for four weeks by phone contact to all study samples after discharge from hospital. Descriptive and inferential statistics were used to analysis of data.

III. RESULTS

Table (1): Types \& Indication of Cesarean Section of Study Sample.

\begin{tabular}{|c|c|c|}
\hline \multirow{2}{*}{ 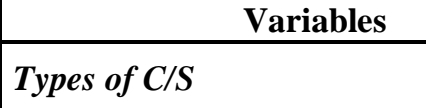 } & \multicolumn{2}{|c|}{ Study group $(\mathrm{n}=30)$} \\
\hline & No. & $\%$ \\
\hline Elective & 17 & 56.7 \\
\hline Emergency & 13 & 43.3 \\
\hline \multicolumn{3}{|l|}{ Indication for $C / S$ for mother } \\
\hline Primipara & 16 & 53.3 \\
\hline Previous $C / S$ & 10 & 33.3 \\
\hline Prolonged of labor & 1 & 3.3 \\
\hline Mother distress & 1 & 3.3 \\
\hline Failure of induction of labor & 10 & 33.3 \\
\hline Constructed pelvic & 1 & 3.3 \\
\hline Oligohydramnios & 1 & 3.3 \\
\hline Post term labor & 2 & 6.7 \\
\hline Placenta previa & 0 & 0 \\
\hline Abruptio placenta & 1 & 3.3 \\
\hline \multicolumn{3}{|l|}{ Indication for $C / S$ for fetus } \\
\hline Fetal distress & 10 & $\underline{33.3}$ \\
\hline Macrosomia & 1 & 3.3 \\
\hline Breech presentation & 6 & $\underline{20}$ \\
\hline \multicolumn{3}{|l|}{ Gender of the baby } \\
\hline Male & 17 & 56.7 \\
\hline Female & 13 & 43.3 \\
\hline \multicolumn{3}{|l|}{ Weight at birth } \\
\hline Normal $(2500-4000) \mathrm{gm}$ & 29 & 96.7 \\
\hline More than (4000) gm & 1 & 3.3 \\
\hline
\end{tabular}

Table (1) shows that the highest percentages (56.7\%) of them have elective $\mathrm{C} / \mathrm{S}$, half of them were primipara, (33.3\%) of them had previous $\mathrm{C} / \mathrm{S}$, and (33.3\%) of them had failure of induction of labor. Concerning the indication of $\mathrm{C} / \mathrm{S}$ for fetus: the highest percentages (33.3\%) of them had fetal distress and $(20 \%)$ had breech presentation. (56.7\%) of them have male newborn and (96.7\%) were within the normal weight (2500-4000) gm.

Table (2): Distributions of Women's Knowledge Regarding Initiation of Breastfeeding ( $\mathrm{n}=30$ ).

\begin{tabular}{|c|l|c|c|c|c|c|}
\hline No. Items & \multicolumn{1}{|c|}{ Yes } & \multicolumn{2}{|c|}{ No } & Mean of \\
score
\end{tabular}




\begin{tabular}{|c|c|c|c|c|c|c|}
\hline 2.1. & Maintain newborn body temperature & 2 & 6.7 & 28 & 93.3 & 1.06 \\
\hline 2.2. & Help in initiation of breastfeeding & 4 & 13.4 & 26 & 86.7 & 1.13 \\
\hline 2.3 . & Nutrition for newborn & 9 & 30 & 21 & 70 & 1.30 \\
\hline 2.4. & Give colostrums for increase newborn immunity & 15 & 50 & 15 & 50 & 1.50 \\
\hline 3. & \multicolumn{5}{|l|}{ What do you mean of colostrums } & \\
\hline 3.1. & Yellowish or creamy-appearing fluid & 14 & 46.7 & 16 & 53.3 & 1.46 \\
\hline 3.2. & Contains larger percentage of protein \& less fat & 2 & 6.7 & 28 & 93.3 & 1.06 \\
\hline 4. & \multicolumn{5}{|l|}{ When the colostrum is secreted after birth } & \\
\hline 4.2. & First day & 1 & 3.3 & 29 & 96.7 & 1.03 \\
\hline 4.3. & Second day & 1 & 3.3 & 29 & 96.7 & 1.03 \\
\hline 4.4. & First three days & 17 & 56.7 & 13 & 43.3 & 1.57 \\
\hline 5. & \multicolumn{5}{|c|}{ What are the benefits of colostrum for the newborn baby } & \\
\hline 5.1. & First immunization for newborn baby & 12 & 40 & 18 & 60 & 1.40 \\
\hline 5.2. & Contain more proteins \& some salts \& vitamins & 1 & 3.3 & 29 & 96.7 & 1.03 \\
\hline 5.3. & Laxative for excretion meconium from bowel & 3 & 10 & 27 & 90 & 1.10 \\
\hline 5.4. & Prevent newborn baby from jaundice & 2 & 6.7 & 28 & 93.3 & 1.06 \\
\hline 5.5. & Improvement chances for growth \& develop... & 3 & 10 & 27 & 90 & 1.10 \\
\hline 6. & \multicolumn{5}{|l|}{ What are the benefits of breastfeeding for mother } & \\
\hline 6.1. & Reduce incidence of postpartum hemorrhage & 1 & 3.3 & 29 & 96.7 & 1.03 \\
\hline 6.2. & Allows the uterus to contract & 3 & 10 & 27 & 90 & 1.10 \\
\hline 6.3. & One method of family planning for six month & 0 & 0 & 30 & 100 & 1.00 \\
\hline 6.4. & Reduce incidence of breast cancer & 2 & 6.7 & 28 & 93.3 & 1.06 \\
\hline 6.5. & Promote maternal weight loss & 3 & 10 & 27 & 90 & 1.10 \\
\hline 6.6. & Strength bonding between mother \& newborn baby & 2 & 6.7 & 28 & 93.3 & 1.06 \\
\hline 6.7. & Mother milk is always available & 1 & 3.3 & 29 & 96.7 & 1.03 \\
\hline 6.8. & Culturally; ideological \& social acceptable & 0 & 0 & 30 & 100 & 1.00 \\
\hline 7. & \multicolumn{5}{|l|}{ What are the benefits of breastfeeding for newborn baby } & \\
\hline 7.1. & Temperature of breast milk is constant & 2 & 6.7 & 28 & 93.3 & 1.06 \\
\hline 7.2. & Best source of nutrition & 11 & 36.7 & 19 & 63.3 & 1.36 \\
\hline 7.3. & Prevent incidence of gastroenteritis & 22 & 73.3 & 8 & 26.7 & 1.73 \\
\hline 7.4. & Improvement of mental development for children & 1 & 3.3 & 29 & 96.7 & 1.03 \\
\hline 8. & $\begin{array}{l}\text { The benefits of breastfeeding for family is saving } \\
\text { money }\end{array}$ & 8 & 26.7 & 22 & 73.3 & 1.26 \\
\hline 9. & $\begin{array}{l}\text { There is the different between the foremilk \& hind } \\
\text { milk }\end{array}$ & 3 & 10 & 27 & 90 & 1.10 \\
\hline 9.1. & Foremilk contain water, vitamins, \& protein & 2 & 6.7 & 28 & 93.3 & 1.06 \\
\hline 9.2. & Hind milk contain fat & 1 & 3.3 & 29 & 96.7 & 1.03 \\
\hline 10. & \multicolumn{5}{|l|}{ Duration of breastfeeding for newborn baby } & \\
\hline 10.1. & $6.1-12$ (months) & 1 & 3.3 & 29 & 96.7 & 1.03 \\
\hline 10.2 . & $12.1-18$ (months) & 2 & 6.7 & 28 & 93.3 & 1.06 \\
\hline 10.3 . & $18.1-24$ (months) & 23 & 76.7 & 7 & 23.3 & 1.76 \\
\hline 10.4. & $>24$ (months) & 2 & 6.7 & 28 & 93.3 & 1.06 \\
\hline 11. & \multicolumn{5}{|c|}{ How long do you belief that mother's milk is enough for newborn baby without any water } & \\
\hline 11.1. & $<1$ (month) & 19 & 63.3 & 11 & 36.7 & 1.63 \\
\hline 11.2. & $1-6$ (months) & 5 & 16.7 & 25 & 83.3 & 1.16 \\
\hline 11.3 & $6.1-12$ (months) & 4 & 13.3 & 26 & 86.7 & 1.13 \\
\hline 11.4 & $12.1-24$ (months) & 1 & 3.3 & 29 & 96.7 & 1.03 \\
\hline 12. & \multicolumn{5}{|l|}{ Duration of exclusive breastfeeding for newborn baby } & \\
\hline 12.1 & Less than 6 month & 1 & 3.3 & 29 & 96.7 & 1.03 \\
\hline 12.2 & 6 months & 1 & 3.3 & 29 & 96.7 & 1.03 \\
\hline 12.3 & More than 6 months & 1 & 3.3 & 29 & 96.7 & 1.03 \\
\hline
\end{tabular}

Table (2) shows that The highest mean score (1.93) related to women's knowledge in initiation of BF in item (1.1): colostrums is the first feeding given to the newborn baby immediately after birth while the lowest mean score in three items (1-1 ): Water \& sugar, item (6.3): One method of family planning for six month and item (6.8): Culturally, ideological \& social acceptable 
Table ( 3 ): Distributions of Women's Practices Regarding Initiation of Breastfeeding ( $\mathrm{n}=30)$.

\begin{tabular}{|c|c|c|c|c|c|c|}
\hline No. & Items & \multicolumn{2}{|c|}{ Yes } & \multicolumn{2}{|c|}{ No } & \multirow{2}{*}{$\begin{array}{c}\text { Mean of } \\
\text { score }\end{array}$} \\
\hline 1. & Initiation of BF after $C / S$ during & No. & $\%$ & No. & $\%$ & \\
\hline 1.1. & 2-4 hours & 0 & 0 & 30 & 100 & 1.00 \\
\hline 1.2. & 4-6 hours & 11 & 36.7 & 19 & 63.3 & $\overline{1.36}$ \\
\hline 1.3. & During 24 hours & 13 & 43.3 & 17 & 56.7 & 1.43 \\
\hline 1.4. & After 24 hours & 4 & 13.3 & 26 & 86.7 & 1.13 \\
\hline \multicolumn{6}{|c|}{$\overline{\bar{x}} \pm$ SD $8.66 \pm 9.57$} & \\
\hline 2. & \multicolumn{5}{|l|}{ Preparation for breastfeeding } & \\
\hline 2.1. & Hand washing with water $\&$ soap & 8 & 26.7 & 22 & 73.3 & 1.26 \\
\hline 2.2. & Breast washing with water \& soap & 1 & 3.3 & 29 & 96.7 & 1.03 \\
\hline 2.3. & Nipple washing with water only & 13 & 43.3 & 17 & 56.7 & 1.43 \\
\hline 2.4 & $\begin{array}{l}\text { Squeeze drops from milk on nipple } \\
\text { before lactation }\end{array}$ & 10 & 33.3 & 20 & 66.7 & 1.33 \\
\hline 2.5 . & Hands wipe by wet napkins & 2 & 6.7 & 28 & 93.3 & 1.06 \\
\hline 3. & \multicolumn{5}{|l|}{ Signs of good attachment for baby is } & \\
\hline 3.1. & Newborn baby attach mother body & 23 & 76.7 & 7 & 23.3 & 1.76 \\
\hline 3.2. & Turn baby toward mother & 24 & 80 & 6 & 20 & 1.80 \\
\hline 3.3. & The baby's chin is touching the breast & 15 & 50 & 15 & 50 & 1.50 \\
\hline 3.4. & The baby's mouth is wide open & 22 & 73.3 & 8 & 26.7 & 1.73 \\
\hline 3.5 . & $\begin{array}{l}\text { Entering part of areola in the baby's } \\
\text { mouth }\end{array}$ & 13 & 43.3 & 17 & 56.7 & 1.43 \\
\hline 3.6. & The baby's lower lips flanged & 2 & 6.7 & 28 & 93.3 & 1.06 \\
\hline 4. & \multicolumn{5}{|c|}{ What are type of positions do you practice during lactation } & \\
\hline 4.1. & Sitting position & 27 & 90 & 3 & 10 & $\underline{1.90}$ \\
\hline 4.2. & Side lying position & 5 & 16.7 & 25 & 83.3 & 1.16 \\
\hline 5. & \multicolumn{6}{|l|}{ How do you practice breastfeeding } \\
\hline 5.1. & On demand & 28 & 93.3 & 2 & 6.7 & 1.16 \\
\hline 5.2. & Schedule & 2 & 6.7 & 28 & 93.3 & 1.83 \\
\hline
\end{tabular}

Table ( 3 ) shows that The highest mean score (1.90) related to women's practices in initiation of BF in item (4.1): assume sitting position during lactation while the lowest mean score in item (1-1 ): initiation of BF after C/S during from 2-4 hours .

Table (4): Maintenance of Breastfeeding Regarding Continuation of Breastfeeding for study sample during Three Sequencing Follow up of Study Sample after Childbirth $(n=30)$

\begin{tabular}{|c|c|c|c|c|c|c|c|c|c|c|c|}
\hline \multirow[t]{2}{*}{ No. } & \multirow[t]{2}{*}{ Items } & \multirow[t]{2}{*}{ Answer } & \multicolumn{3}{|c|}{$\begin{array}{c}\text { First follow up }\left(2^{\text {nd }}\right. \\
\text { week })\end{array}$} & \multicolumn{3}{|c|}{$\begin{array}{l}\text { Second follow up } \\
\left(3^{\text {rd }} \text { week }\right)\end{array}$} & \multicolumn{3}{|c|}{$\begin{array}{l}\text { Third follow up }\left(4^{\text {th }}\right. \\
\text { week) }\end{array}$} \\
\hline & & & No. & $\%$ & MS & No. & $\%$ & MS & No. & $\%$ & MS \\
\hline \multirow{2}{*}{1} & \multirow{2}{*}{ Do you continue on $\mathrm{BF}$} & Yes & 25 & 83.3 & \multirow{2}{*}{1.83} & 22 & 73.3 & \multirow{2}{*}{1.73} & 23 & 76.7 & \multirow{2}{*}{1.77} \\
\hline & & No & 5 & 16.7 & & 8 & 26.7 & & 7 & 23.3 & \\
\hline 2. & \multicolumn{11}{|l|}{ Lactation from both breasts } \\
\hline \multirow{3}{*}{2.1} & \multirow{3}{*}{$\begin{array}{l}\text { Change of breast during } \\
\text { lactation in each feeding }\end{array}$} & Yes & 17 & 68 & \multirow[t]{3}{*}{1.68} & 13 & 59 & \multirow[t]{3}{*}{1.59} & 14 & 61 & \multirow[t]{3}{*}{1.61} \\
\hline & & No & 8 & 32 & & 9 & 41 & & 9 & 39 & \\
\hline & & No & 19 & 76 & & 15 & 68 & & 16 & 69.7 & \\
\hline \multirow{2}{*}{2.2} & \multirow{2}{*}{$\begin{array}{l}\text { Baby prefers one breast in } \\
\text { feeding }\end{array}$} & Yes & 2 & 8 & \multirow[t]{2}{*}{1.08} & 2 & 9 & \multirow[t]{2}{*}{1.09} & 2 & 8.7 & \multirow[t]{2}{*}{1.09} \\
\hline & & No & 23 & 92 & & 20 & 91 & & 21 & 91.3 & \\
\hline \multirow{2}{*}{3} & \multirow{2}{*}{$\begin{array}{l}\text { practice breastfeeding on } \\
\text { demand }\end{array}$} & Yes & 25 & 100 & \multirow[t]{2}{*}{2.00} & 22 & 100 & \multirow[t]{2}{*}{2.00} & 23 & 100 & \multirow[t]{2}{*}{2.00} \\
\hline & & No & 0 & 0 & & 0 & 0 & & 0 & 0 & \\
\hline 4 & \multicolumn{11}{|l|}{ Type of positioning } \\
\hline \multirow{2}{*}{4.1} & \multirow{2}{*}{ Sitting position } & Yes & 25 & 100 & \multirow[t]{2}{*}{2.00} & 22 & 100 & 2.00 & 23 & 100 & 2.00 \\
\hline & & No & 0 & 0 & & 0 & 0 & & 0 & 0 & \\
\hline 12 & Sidoluing prition & Yes & 4 & 16 & 1.16 & 2 & 9 & 1.09 & 3 & 13 & 1.13 \\
\hline 4.2 & Side lying position & No & 21 & 84 & & 20 & 91 & & 20 & 87 & \\
\hline 5 & Complain of any problems $\mathrm{d}$ & aring BF & & & & & & & & & \\
\hline & & Yes & 6 & 24 & 1.76 & 5 & 22.5 & 1.77 & 0 & 0 & 2.00 \\
\hline 5.1 & Nipple sore & No & 19 & 76 & & 17 & 77.3 & & 23 & 100 & \\
\hline 50 & Enoromemont & Yes & 3 & 12 & 1.88 & 3 & 13.7 & 1.86 & 0 & 0 & 2.00 \\
\hline 5.2 & Engorgement & No & 22 & 88 & & 19 & 86.3 & & 23 & 100 & \\
\hline & & Yes & 0 & 0 & 2.00 & 0 & 0 & 2.00 & 1 & 4.3 & 1.95 \\
\hline 5.3 & Nipple pain & No & 25 & 100 & & 22 & 100 & & 22 & 95.7 & \\
\hline
\end{tabular}


The table (4) revealed that the highest mean score ( 2.00) of them preferred to feed their baby on demand on three subsequences follow up while the lowest mean score (1.9) of them prefer to feed their baby on one breast during single feeding.

Table (5): Reasons for Discontinuation of Breastfeeding during Three Sequencing Follow up after Childbirth.

\begin{tabular}{|l|c|c|c|c|c|c||}
\hline \multicolumn{1}{|c|}{ Items } & \multicolumn{2}{|c|}{$\begin{array}{l}\text { First follow up } \\
\left(2^{\text {nd }} \text { week }\right) \text { n=5 }\end{array}$} & \multicolumn{2}{c|}{$\begin{array}{c}\text { Second follow up } \\
\left(3^{\text {rd }} \text { week }\right) \text { n=8 }\end{array}$} & $\begin{array}{c}\text { Third follow up } \\
\left(4^{\text {th }} \text { week }\right) \text { n=7 }\end{array}$ \\
\hline $\begin{array}{l}* \text { Reasons for discontinuation } \\
\text { of BF }\end{array}$ & No. & $\%$ & No. & $\%$ & No. & $\%$ \\
\hline Not enough milk & 2 & $\underline{40}$ & 3 & $\underline{37.5}$ & 2 & 28.7 \\
\hline Don't sleep between feeding & 2 & 40 & 1 & 12.5 & 1 & 14.3 \\
\hline $\begin{array}{l}\text { Excretion stool less than two } \\
\text { time daily }\end{array}$ & 0 & 0 & 0 & 0 & 1 & 14.3 \\
\hline Don't increase baby weight & 1 & 20 & 0 & 0 & 0 & 0 \\
\hline Pain in the breast & 1 & 20 & 1 & 12.5 & 1 & 14.3 \\
\hline $\begin{array}{l}\text { The newborn baby refuse } \\
\text { lactation }\end{array}$ & 1 & 20 & 3 & $\underline{37.5}$ & 4 & $\underline{57}$ \\
\hline Problems in the nipple & 1 & 20 & 1 & 12.5 & 0 & 0 \\
\hline The newborn baby sick & 1 & 20 & 2 & 25 & 1 & 14.3 \\
\hline
\end{tabular}

* More than one answer

The table (5) shows that the highest percentage (40\%) did not have enough milk during first follow up as a reasons for discontinuation of breastfeeding during first and second follow up while the highest percentage $(57 \%)$ the newborn baby refused lactation as a reasons for discontinuation of breastfeeding during third follow up.

Table ( 6 ): Predication the Variables Contribute in Initiation of Breastfeeding by using Simple Linear regression.

\begin{tabular}{|c|c|c|c|c|c|c|}
\hline \multicolumn{2}{|c|}{ Variables } & \multicolumn{5}{c|}{ study Group } \\
\hline Independent & Dependent & R & df & F & Sig. & C.S. \\
\hline Age & *K. \& P. & 0.406 & 28 & 5.550 & 0.026 & S \\
\hline Educational level & K. \& P. & 0.138 & 28 & 0.550 & 0.464 & NS \\
\hline Occupation & K. \& P. & 0.063 & 28 & 0.100 & 0.752 & NS \\
\hline Socioeconomic Status & K. \& P. & 0.105 & 28 & 0.320 & 0.579 & NS \\
\hline Parity & K. \& P. & 0.422 & 28 & 6.080 & 0.020 & S \\
\hline No. of Alive children & K. \& P. & 0.422 & 28 & 6.080 & 0.020 & S \\
\hline Age at marriage & K. \& P. & 0.386 & 28 & 4.900 & 0.035 & S \\
\hline Place of previous delivery & K. \& P. & 0.422 & 28 & 6.080 & 0.020 & S \\
\hline previous initiation of BF & K. \& P. & 0.371 & 28 & 4.470 & 0.044 & S \\
\hline Gender of the baby & K. \& P. & 0.332 & 28 & 3.470 & 0.073 & NS \\
\hline
\end{tabular}

* K. refers to Knowledge P. refers to Practices

Table (6) revealed that age, parity, number of alive children, age at marriage, place of previous delivery and previous initiation of breastfeeding were the predication variables which contribute in initiation of breastfeeding (knowledge \& practices) in study sample.

\section{DISCUSSION}

The present study reveals that the highest percentages (36.7\%) at age group (20-24) years and the mean with standard deviation (SD) of age for both groups were $(23.7 \pm 6.46)$. and there is an association between the age and initiation of breastfeeding (knowledge \& practices) as shown in table (6). It was found that the significance of the age differentials in the initiation of breastfeeding decreased considerably when socioeconomic and demographic factors were controlled. A significant difference remained only between very young mothers aged 15 years and those aged 20-29 years. More than 25 years are more likely to initiate and 
continue $\mathrm{BF}$ than younger women ${ }^{(4)}$. In general, a younger maternal age, especially under the age of 18 years, is thought to be related to a significantly shorter duration of actual and intended breastfeeding. Older mothers, typically women over the age of 30 years, are reported to be more likely to initiate breastfeeding, and to continue this act for a longer period of time ${ }^{(5)}$. In other studies of Middle Eastern women, there was no positive association was found between maternal age \& initiation of breastfeeding in Kuwait, United Arab Emirates (UAE) \& Saudi Arabia ${ }^{(6)}$. The level of education plays a large role in influencing a woman to breastfeed the child. It has been found that mothers with a higher education level tend to initiate breastfeeding more often, and also tend to breastfeed their child for a longer period of time than do their less educated counterparts ${ }^{(7)}$. The present study reveals that the majority of study sample (93.3\%) were housewives. The present study also reveals that there is no association between occupation \& initiation of breastfeeding (knowledge \& practices) as shown in table (6). Maternal employment is a factor that has received much acknowledgement in influencing a mother's decision to breastfeed the child ${ }^{(8)}$.

The present study reveals that the highest percentages (96.7\%) were from urban area. It was reported that the Iraq is experiencing rapid urbanization. An increasingly urban lifestyle can lead to alterations in traditional behaviors such as BF. In addition, evidence shows that maternal education, social class, ethnic background and religion are related to the decision to initiate and continue $\mathrm{BF}^{(9)}$. The present study reveals that the highest percentage (60\%) was in moderate socioeconomic status. The present study also reveals that there is no association between socioeconomic status \& initiation of breastfeeding (knowledge \& practices) as shown in table (6). Women from lower-income families are less likely to breastfeed for a number of reasons, including less family support for breastfeeding, less ability to seek help with breastfeeding problems, less flexibility with working arrangements, and concerns about breastfeeding in public ${ }^{(10)}$. The present study reveals that more than half of study sample were primigravida and multiparous. The present study also reveals that there is an association between parity \& initiation of breastfeeding (knowledge \& practices) as shown in table (6). Some authors have found that primiparous women are more likely to initiate breastfeeding than multiparas, but multiparous women breastfeed for longer periods of time ${ }^{(11)}$. The present study reveals that the more than half of study sample had first alive children.

The present study reveals that the highest percentage $(71.5 \%)$ show that their initiate breastfeeding during 24 hours. The present study also reveals that there is an association between previous initiation \& initiation of breastfeeding (knowledge \& practices) as shown in table (6). Multiparous women with a previous negative breastfeeding experience are likely to need support to attempt to breastfeed again. Previous studies indicated that if the breastfeeding experience is positive, breastfeeding can increase positive maternal affect ${ }^{(12)}$.

The present study reveals that the highest percentage (56.7\%) have elective C/S. Regardless to the type of cesarean section mothers who delivered by caesarean section were at 1.9 times more risk of stopping breast feeding and showed shorter duration of lactation than those who delivered vaginally. This could be for several reasons related to the mother's and infant's health after delivery which influences the decision to breastfeed and maintain lactation. In addition, the mother's feeling that she has failed to deliver normally by the vaginal route and her fear of harming her infant through insufficient milk intake make her support the use of artificial feeding. Previous studies have reported that caesarean section delivery was a risk factor for not initiating breastfeeding, and that infants delivered by caesarean section started suckling later and were given bottles more often during the first days of life. This, in addition to lack of antenatal and postnatal education to guide the mother into initiating lactation and maintaining it through regular and extensive breastfeeding, certainly influences the infant's feeding pattern ${ }^{(13)}$. The present study reveals that the highest percentage $(73.3 \%)$ did not have any advices or instructions about breastfeeding $(23.3 \%)$ the family \& mother was a source of knowledge about breastfeeding. Family members including mother, mother in law and baby's grandmothers can play critical support role, both with regard assisting in decision-making about how the baby is fed and providing support for breastfeeding after the baby is born ${ }^{(2)}$. Health care providers have an important impact on intention to breastfeed, initiation and consequent duration of breastfeeding. Commencement of early breastfeeding was associated with the proportion of mothers who fully breastfed their infants up to four months. After cesarean section, a mother should continue to feed the baby on demand, but she will need help for a few days to hold the baby, to learn how to breastfeed lying down, and to turn over and to position herself comfortably for feeds. Hospital staff and family members can all help the mother in this way. Most mothers can breastfeed normally after a cesarean delivery if they are given appropriate help, usually about 4 hours after delivery. In our study population, women having a caesarean section had lower rates of exclusive breastfeeding than with vaginal delivery. Due to the feeling of pain in their abdominal incision, movement is limited because of catheterization and intravenous lines, and Chinese mothers worry about the side effects of medicines which may pass to the baby via breast milk ${ }^{(14)}$. The decrease in exclusive breastfeeding in the study sample could have been due to a misconception among mothers and their families about the early introduction of water and other liquids (i.e. artificial milk) and of food supplements to their infants. Continuous breastfeeding education of mothers and their close relatives, with special emphasis on the advantages of exclusive breastfeeding during the first months 
of life, would therefore help to improve their knowledge and lead to the adoption of healthy practices. At the end of the first follow up ( $2^{\text {nd }}$ week), the rates of exclusive breastfeeding was $(28 \%)$ by the end of second follow was $(22.7 \%)$ and $\left(4^{\text {th }}\right.$ week) the rates was $(26 \%)$. The majority of mothers believe that 'exclusive breastfeeding' cannot satisfy their baby's need for food until six months. Because of this the majority of babies were fed infant formula or solid food before four months. Breastfeeding education during the antenatal period or in hospital does not seem to be enough to counter parent influences of traditional beliefs and modern television commercials. Social support helps reduce maternal stress by providing a mechanism for individuals to access information, receive emotional support, and get help as they cope with stressors caused by the newness of motherhood ${ }^{(15)}$. The present study also reveals that the main reasons for discontinuation of breastfeeding is not enough milk in addition ,the newborn refused lactation as shown in table (5). Breast problems such as sore and inverted nipples, and mastitis were very common in breastfeeding mothers especially in the first month ${ }^{(16)}$. Conclusion: Most study sample was primipara, previous $\mathrm{C} / \mathrm{S}$, fetal distress \& breech presentation as indication for $\mathrm{C} / \mathrm{S}$ and had born male baby with normal weight. The main source of advice \& instruction in breastfeeding was mother \& mother in law. Nearly two third of them had continuation of breastfeeding and quarter of them were exclusive breastfeeding. The main reasons for discontinuation of breastfeeding are not enough milk \& newborn refuse lactation. Predication variables which contribute in initiation of breastfeeding (knowledge \& practices) in study sample included six factors, which were the following: age, parity, number of alive children, age at marriage, place of previous delivery and previous initiation of breastfeeding.

\section{RECOMMENDATIONS}

In-services education for the nurse's regarding knowledge of the current evidence, and provides experience in the skills necessary to fulfill their responsibility to support breastfeeding. Reactivate the role of breastfeeding in promoting of breastfeeding by the implementation ten steps successful of breastfeeding \& organization should ensure that health workers providing breastfeeding support \& receive education appropriate to their role in breastfeeding in order to develop the knowledge, skill, and attitude to implement breastfeeding policy \& to support lactating mothers. Education \& breastfeeding counseling for women during pregnancy and after childbirth which has important role on initiation \& maintenance of breastfeeding up to 6 months and distribution of breastfeeding booklet of the instructional material to all mothers having $\mathrm{C} / \mathrm{S}$ or normal vaginal delivery and implementing LATCH breastfeeding assessment tool for women after childbirth.

\section{REFERENCES}

[1] Alemayehu T., Haidar J. \& Habte D.: Determinants of exclusive breastfeeding practices in Ethiopia, Ethiop.J.Health Dev., 2009, 23(1):12-18..

[2] U.S. Department of Health and Human Services, Healthy People 2010: With Understanding and Improving Health and Objectives For Improving Health, 2nd ed., Washington, DC, US Government Printing Office, 2000.

[3] Pérez-Escamilla R., Maulěn-Radovan I. \& Dewey K.: The association between cesarean delivery and breast-feeding outcomes among Mexican women, Am J Public Health, 1996, 86(6):832-836.

[4] Forster D., Mclachlan H. \& Lumley J.: Factors associated with breastfeeding at six months postpartum in a group of Australian women [online], International Breastfeeding Journal, 2006, 1(18):1-12. Available at: http://www.internationalbreastfeedingjournal.com/content/ 1/1/18

[5] Murtaugh M.: Optimal breastfeeding duration [online], Journal of the American Dietetic Association, 1997, 97: 1252-1254.

[6] Dashti M., Scott J., Edwards C. \& Al-Sughayer M.: Determinants of breastfeeding initiation among mothers in Kuwait [online], International Breastfeeding Journal, 2010, 5(7):1-9. Available at: http://www. internationalbreastfeedingjournal.com/content/5/1/7

[7] Shelton M. \& Qi Wang M.: Demographic factors associated with the duration of mothers' breastfeeding, American Journal of Health Studies, 1997, 13: 195-200.

[8] Fein S. \& Roe B.: The effect of work status on initiation and duration of breastfeeding, American Journal of Public Health, 1998, 88:1042-1047.

[9] Abdul Ameer A., Al-Hadi A-H. \& Abdulla M.: Knowledge, attitudes and practices of Iraqi mothers and family child-caring women regarding breastfeeding, Eastern Mediterranean Health Journal, 2008, 14 (5): 1003-1014.

[10] Amir L. \& Donath S.: Socioeconomic status and rates of breastfeeding in Australia: evidence from three recent national health surveys, The Medical Journal of Australia, 2008, 189 (5):254-256.

[11] Ford K. \& Labbok M.: Who is breastfeeding? Implications of associated social and biomedical variables for research on the consequences of method of infant feeding, American Journal of Clinical Nutrition, 1990, 52: 451-456. 
[12] McHale H. \& Gutmanis I.: Breastfeeding Duration Rates in Middlesex London, Ontario, MiddlesexLondon Health Unit, 1999: 50-51.

[13] Shawky S. \& Abalkhail B.: Maternal factors associated with the duration of breast feeding in Jeddah, Saudi Arabia, Paediatric and Perinatal Epidemiology, 2003, 17: 91-96

[14] Qiu L., Zhao Y., Binns C., Lee A. \& Xie X.: Initiation of breastfeeding and prevalence of exclusive breastfeeding at hospital discharge in urban, suburban and rural areas of Zhejiang China [online], International Breastfeeding Journal, 2009, 4(1):1-7. Available at: http://www.interna tionalbreastfeedingjournal.com/con tent /4/1/1

[15] Bonuck K., Trombley M., Freeman K. \& McKee D.: Randomized, controlled trial of a prenatal and postnatal lactation consultant intervention on duration and intensity of breastfeeding up to 12 months, Pediatrics, 2005, 116(6): 1413-1426.

[16] Xu F., Qiu L., Binns C. \& Liu X.: Breastfeeding in China: a review [online], International Breastfeeding Journal, 2009, 4(6):1-15. Available at: http://www.internationalbreastfeedingjournal.com/ content/4/1/6 